\title{
From brown shore to green shore: redevelopment of the Southeast False Creek lands in Vancouver, Canada
}

\author{
B. G. Wernick ${ }^{1}$, L. H. Nikl ${ }^{1} \&$ M. A. Adams ${ }^{2}$ \\ ${ }^{1}$ Golder Associates Ltd., Canada \\ ${ }^{2}$ Envirowest Consultants Ltd., Canada
}

\begin{abstract}
The Southeast False Creek (SEFC) lands in Vancouver, Canada, had a long history of industrial use and filling prior to their redevelopment first for use as the 2010 Winter Olympic Village and now as a continuation of the residential community along highly-sought-after city waterfront lands. Soil and sediment concentrations of metals and hydrocarbons exceeded regulatory benchmarks in and around a man-made embayment that supported ship building and steel fabrication. As well, the shoreline was highly disturbed with debris, erosion, and non-native vegetation, and consequently limited in its ability to support intertidal species typically expected in coastal waters of Western Canada.

The Official Development Plan prepared by the City of Vancouver for SEFC incorporated shoreline improvements to public access, fish habitat, and safety and health objectives in response to community values expressed during an extensive public consultation process. Remediation and reconfiguration of the SEFC shoreline was thus a significant component of redevelopment which included removal of contaminated sediment and soil; filling of a portion of the embayment; stabilization, re-dressing, and planting of the remainder of the existing shoreline; and construction of an island in compensation for the partial filling of the embayment.

Three annual surveys of a five-year post-construction monitoring program have been undertaken to date to evaluate the function of the constructed habitat and reconfigured shoreline. Both continue to be colonized by macroalgae and sessile invertebrates, and coverage and community structure is becoming more
\end{abstract}


similar to reference areas. As well, several species of culturally, recreationally, and commercially important fish are using the habitat.

Keywords: brownfield development, remediation, habitat compensation, habitat offsets, aftercare monitoring, post-construction monitoring.

\section{Introduction}

The Southeast False Creek (SEFC) lands are located in Vancouver, Canada $\left(49^{\circ} 16^{\prime} 20^{\prime \prime} \mathrm{N} / 123^{\circ} 06^{\prime} 33^{\prime \prime} \mathrm{W}\right)$. False Creek is a natural inlet that used to extend some kilometres east as a large wetland complex. In the early 1900s and following significant filling, the shoreline of False Creek was lined with sawmills, shingle mills and other construction industries including a shipyard that built naval ships during World War I [1]. Additional filling in the 1920s and later in the 1940s resulted in the formation of a small embayment that was used for storage and water transportation for a steel fabrication plant that was built on the former shipyard site in 1935 and continued operating in what became known as the Canron building until 1990; the building itself was demolished in 1998 . Wood decking was put into place over the Canron embayment in the 1950s. Following the decline of industrial activity around SEFC and the temporary use of the site for the 1986 World Exposition, the lands were largely vacant and consisted of either gravel or paved lots.

Planning for the redevelopment of the SEFC lands was initiated in 1998, first with the preparation of a policy statement that took into account the feedback received during stakeholder meetings and large public workshops. Additional public events were held in 2003, during which the Official Development Plan (ODP) Proposal was presented. A revised draft ODP was presented for further public comment in 2004, and the Vancouver City Council approved the ODP in 2005. The ODP incorporated shoreline improvements to public access, fish habitat, and safety and health objectives vis-à-vis site remediation, in response to community values expressed during the public consultation process. The ODP covers an area of about 32 ha that will eventually include about $560,000 \mathrm{~m}^{2}$ of development and be home to up to 15,000 residents, with the waterfront becoming part of the City's park system. The redevelopment activities were initiated with the construction of the 2010 Winter Olympic Village on 10\% of the SEFC lands to house 2,200 athletes attending the games and the buildings are now in the process of being sold as market housing.

This paper provides an overview of the transformation of a post-industrial brownfield site into an engaging public realm and the simultaneous transformation of low-quality, contaminated aquatic habitat to a productive intertidal and subtidal marine ecosystem situated within a major metropolitan area. The pre-development condition of the SEFC shoreline is described at an overview level and the recovery of the intertidal community following remediation and reconfiguration of the shoreline is documented. 


\section{Pre-development condition of the site}

A temporary asphalt pathway bordered by ornamental, non-native trees and shrubs (e.g., Himalayan blackberry [Rubus sp.] and Scotch broom [Cytisus scoparius]) planted for the 1986 World Expo extended along the top of bank. The shoreline to the east of the Cambie Bridge, fig. 1, was stabilized with granite riprap and sheet piling. East of the sheet-piled area to the east edge of the Olympic Village lands, the profile of the bank was relatively steep (2H:1V) and attempts to stabilize the shoreline in places relied on the (non-engineered) use of construction debris including pieces of concrete, asphalt and steel. Ongoing erosion and sloughing of material off the slope was evident. The former Canron embayment was occupied by dilapidated wooden decking supported by creosotetreated timber pilings, and underlain by riprap. The area under the deck was intertidal and consisted of mud, with some sand and gravel, littered with debris (e.g., bricks, wood, metal, glass, sandblasting grit).

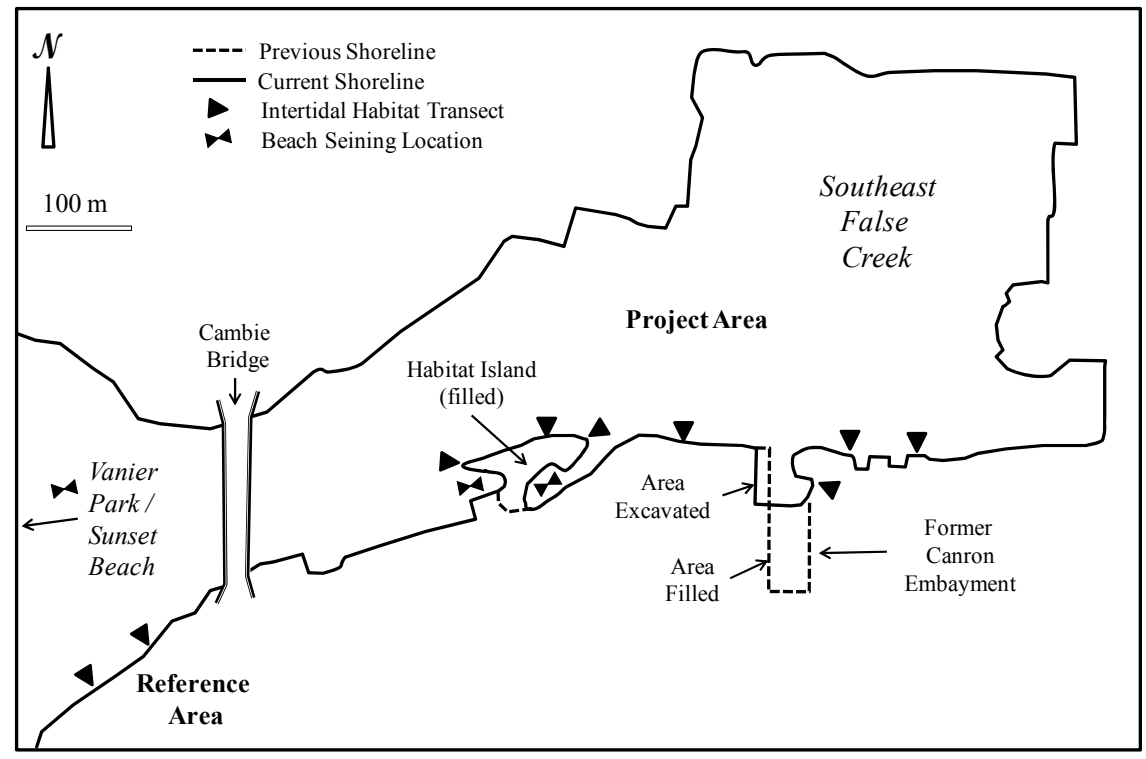

Figure 1: Study locations in Southeast False Creek.

A quantitative assessment of the biological community inhabiting the shoreline was not conducted prior to the shoreline reconfiguration; however, the visual observations of the authors were that the intertidal species expected to be present were there. Fucus gardneri and Mastocarpus sp. were found in the upper zone, Ulva sp. and Enteromorpha sp. in the mid intertidal, and brown (Laminaria saccharina, Alaria sp. and Costaria sp.) and red (Iridaea sp.) macroalgae in the lower intertidal and shallow subtidal zones. Barnacles (Balanus sp.) and mussels (Mytilus sp.) were observed encrusting the hard surfaces of the sheet pile wall and riprap. Due to the instability of the substrate, 
however, coverage by these species was generally lower than observed in other areas of False Creek where the shoreline was stable. Intertidal habitat diversity was low, as it has been along the modified shoreline of False Creek where hard substrates (placed rock, concrete and demolition debris) are common.

Site investigations conducted between 1989 and 2003 (summarized in [2]) indicated that fill materials were generally contaminated with metals at concentrations exceeding the British Columbia Contaminated Sites Regulation (CSR) for residential land (RL) and urban park (PL) use. At some locations, fill materials were also contaminated with light and heavy extractable petroleum hydrocarbons (EPH) and/or polycyclic aromatic hydrocarbons (PAH) at concentrations exceeding the RL and PL standards. The soil in the area around the embayment occupied by the steel fabrication plant functioned as a source of ongoing groundwater contamination, by zinc in particular. The subtidal sediments in the embayment were also contaminated with zinc, and sediment toxicity tests using the amphipod Eohaustorius estuarius and the bivalve Mytilus edulis identified that the sediments at the end of the embayment were toxic and had a benthic macroinvertebrate community structure indicative of impairment. However, this portion of the bay was scheduled to be excavated and backfilled; testing carried out in the habitat compensation area and along the shoreline provided evidence that contamination was unlikely to impair the success of the habitat. Subsequent monitoring was carried out, in part, to confirm this finding and in part to verify the colonization and function of the constructed habitat.

\section{Redevelopment of the site}

The reconfiguration of the shoreline was a significant component of the site redevelopment and included the following works:

- Remediation (removal and off-site disposal) of contaminated sediment and soil in the former Canron embayment. This included permanent removal of material to a point $5 \mathrm{~m}$ west of the boundary of the original embayment;

- Filling of part of the former Canron embayment with clean material, followed by installation of steel sheet piles on the south and west sides, and placement of architectural granite blocks on the east side; and,

- Stabilization and re-dressing of the shoreline with a mixture of architectural granite blocks as well as graded riprap with pocket plantings of intertidal marsh plants.

In Canada, the federal Fisheries Act governs changes to fish habitat and contains a general prohibition against the harmful alteration, disruption, or destruction (HADD) of fish habitat unless authorized. One of the major themes of policy guiding the application of the Fisheries Act requires that there be no net loss (NNL) of fish habitat; a means to achieving this goal is the construction of new habitats to compensate for habitat losses [3]. Thus, a final component of the shoreline works in SEFC included the construction of an island within the harbour headline to compensate for the loss of habitat associated with the partial 
filling of the embayment. A feature of Canada's aquatic habitat management policy is that the productive capacity of the habitat must, if altered or destroyed, be offset with new capacity constructed. The productivity of the habitat is not relevant and thus contaminated habitats that are lost must also be offset. This policy resulted in beneficial outcomes for the public realm, property values and marine ecology.

The island was constructed of materials sized to maximize interstitial voids to promote a diverse and abundant assemblage of motile invertebrates, as well as surface area for the attachment of invertebrates and macroalgae which were expected to colonise naturally. Between the island and the main shore are shallow-sloping (i.e., $>10 \mathrm{H}: 1 \mathrm{~V}$ ) intertidal channels with cobble and gravel material; this habitat type was largely absent from False Creek following the historical filling. The surface dressing of the main shoreline included the placement of graded riprap with pocket plantings of species such as reed grass (Calamagrostis acutiflora), tufted hair grass (Deschampsia caespitose), and dunegrass (Elymus mollis). On Habitat Island, the surface materials consisted of rounded materials more characteristic of natural shorelines. The compensatory habitat design is further discussed in Adams et al. [4].

\section{Post-construction habitat monitoring program}

\subsection{Objective}

In fulfilment of conditions included in the regulatory Authorization for the project, a five-year post-construction monitoring program was implemented. The purpose of the monitoring program was "to assess the form and function of the compensatory fish habitats and their success as fish habitat" (excerpt from the Authorization) and was to include annual assessments of the colonization of the substrate as well as an assessment of fish usage.

\subsection{Methods}

The methodology was developed in collaboration with regulatory agency staff prior to the first monitoring event in 2008. The second year of monitoring was delayed during 2010 due to occupancy of the SEFC lands and intertidal areas by the Vancouver Olympic Committee from October 2009 to April 2010 for the 2010 Winter Olympic Games and associated security provisions. Year 3 of the monitoring program was conducted in 2011.

\subsubsection{Assessment of fish utilization}

Fish collection was conducted during each monitoring event under the authority of a federal license issued for the collection of fish for scientific purposes. The timing of fish collection activities (late May) was planned to coincide with when juvenile salmonids were likely to be present in False Creek [5]. Fish collection was conducted over two days to allow for sampling during consistent tidal heights among sampling events (generally 2 to $3 \mathrm{~m}$, chart datum at Vancouver). 
Four sampling locations were selected, fig. 1, one in each of the intertidal channels on the east and west sides of the compensatory as well as at two reference sites (Vanier Park and Sunset Beach at the mouth of False Creek) with similar habitats (generally shallow-sloping intertidal areas with cobble/gravel and sand substrates). Each location was seined (15 m wide $\mathrm{x} 1.5 \mathrm{~m}$ deep beach seine) from the maximum wading depth towards the shore for two or three passes of approximately 20 to $40 \mathrm{~m}$ in length depending on the location. Collected fish were identified and enumerated and fork length was measured. All captured fish were returned unharmed to False Creek outside of the sampling area.

\subsubsection{Intertidal community assessment}

Typical intertidal habitat in False Creek consists of a wide range of coverage and diversity of flora and fauna which can be considered functional fish habitat. It was not the intention of this study to assess the full range of potential habitat conditions in SEFC which are variable due to differences in physical substrate characteristics and changing conditions such as tides, currents, solar radiation, sedimentation and presence of stressors from multiple sources not related to the site. Therefore, the "success as fish habitat" of the Project Area was not defined as "statistical" similarity to the selected "reference" transects.

Sampling took place during one or two low tide events in December 2008 (tide height $=0.1 \mathrm{~m}$ ), August 2010 (tide height $=1.2 \mathrm{~m}$ ) and August 2011 (tide height $=0.9 \mathrm{~m}$ ). Intertidal community assessment along the Pacific coast is preferably conducted during the summer to take advantage of day-time lower low tides. However, due to timing constraints associated with meeting permit conditions, the first sampling event was conducted during a winter night-time lower low tide. Following the delay in the monitoring program associated with the Olympics, the field work was rescheduled to late summer.

Nine sampling reaches were selected to capture a range of habitat types (e.g., intertidal bank versus flat) at the site while maintaining relatively consistent aspect, slope and substrates where possible, and included four transects along the eastern shoreline of the site, three transects on the compensatory island habitat, and two transects in a reference area west of the site, fig. 1. The transects were generally oriented south to north except for the transects on either end of Habitat Island, which were oriented east to west. Transects along the eastern shoreline of the project area consisted primarily of angular boulders (ca. $>250 \mathrm{~mm}$ ), with the exception of the transect in the embayment where architectural blocks (ca. $500 \mathrm{~mm}$ deep x 1,500 mm wide) were fitted closely together in a step-like configuration in the high to mid intertidal zone, with cobbles (ca. 50 to $250 \mathrm{~mm}$ ) and gravel (ca. 2 to $50 \mathrm{~mm}$ ) in the mid to low intertidal zone. The substrate of the transects on the east and west shores of the Habitat Island was a mixture of rounded boulders, cobble, and gravel. The transect on the north side of Habitat Island consisted of boulder materials similar to the eastern shoreline. The reference reaches consist generally of cobbles and boulders.

One transect was established at each reach and was oriented perpendicular to the shoreline. For each transect a $1 \mathrm{~m} \mathrm{x} 1 \mathrm{~m}$ quadrat (strung at $10 \mathrm{~cm}$ intervals 
along each axis to facilitate estimation of coverage) was placed in the low, middle and high intertidal zone. During the first annual survey, the distance from the top of the bank at a defined point to the location of the placement of the quadrat in each intertidal zone was recorded to facilitate return to the same part of the zone during subsequent surveys. The percent substrate that was bare, as well as that covered by macro-algae and sessile invertebrates visible from above, was visually estimated within the quadrat on the basis of five coverage categories (i.e., 0 : 0 to $1 \% ; 1: 1$ to $<5 \% ; 2: 5$ to $<25 \% ; 3: 25$ to $<50 \%$; $4: 50$ to $<75 \%$; 5: 75 to $100 \%$ ). Species identification was to the lowest possible taxonomic level (i.e., family, genus, species). In cases where positive identifications could not be performed to the species level, organisms were identified according to the next higher taxonomic level (i.e., family, order, class, phylum). Macrophytes and invertebrates were identified using applicable identification keys [6-8]. The presence of motile species in the quadrats was noted as well, but no relative measure of density was made.

For calculation of summary statistics, a single point coverage was derived by taking the mid-point for each coverage category (e.g., for category 3, a point coverage of $37.5 \%$ was assigned). The mean coverage \pm standard deviation (SD) was calculated separately for the Project Area ( $n=7$ for each intertidal zone) and the reference area $(n=2)$. Non-metric multidimensional scaling (NMDS) was used to assess differences in intertidal community structure among sites and sampling events on the basis of proportion of bare substrate as well as coverage by major taxa (i.e., Prasiola sp., Cladophora sp. Fucus gardneri, Balanus glandula, Mytilus sp.). The point coverage values were $\log 10(\mathrm{x}+1)$ transformed prior to analysis. Spearman rank correlations between the taxa coverage transformed values and the NMDS dimensions identified which invertebrate taxa were most closely associated with each dimension. The NMDS ordination and Spearman rank correlations were conducted in $\operatorname{Systat}^{\circledR} 11$.

\subsection{Results}

\subsubsection{Fish utilization}

Juveniles (3 to $14 \mathrm{~cm}$ fork length) of four Pacific salmon species (chinook [Oncorhynchus tshawytscha]; chum [O. keta]; coho [O. kisutch]; and steelhead [O. mykiss]) were collected from one or more site, as were three-spine stickleback (Gasterosteus aculeatus), Pacific sand lance (Ammodytes hexapterus), staghorn sculpin (Leptocottus armatus), banded gunnel (Pholis fasciata) and shiner perch (Cymatogaster aggregata). The highest species richness and highest total number of fish collected were generally from the reference site, Vanier Park outside False Creek, where the catch was dominated by shiner perch. Richness and abundance at Habitat Island were similar to that observed at the second reference site, Sunset Beach.

A comparison of the total number of salmonids, a valued commercial, recreational and culturally significant taxon, caught among years is presented in fig. 2. Similar numbers of salmonids were collected between locations in each given year. 


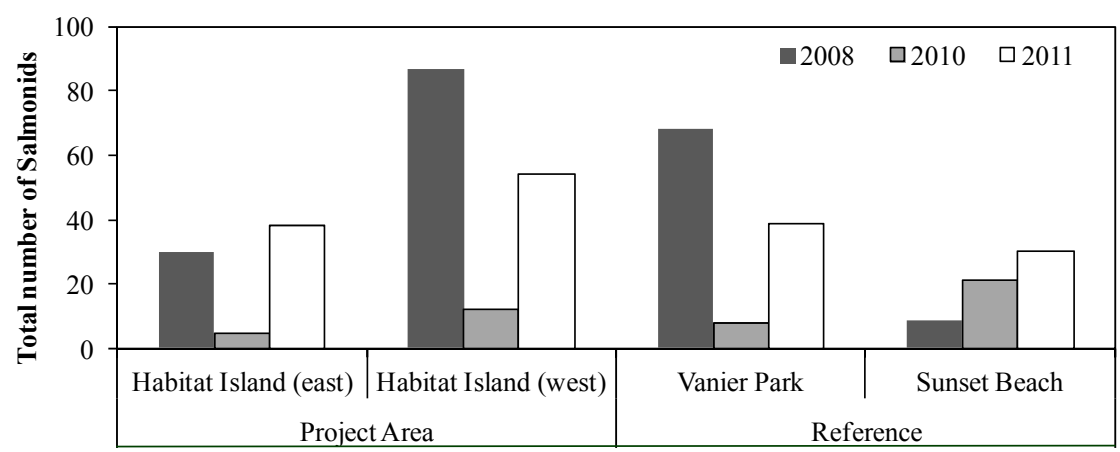

Location

Figure 2: Comparison of numbers of salmonid fish caught among survey years and areas.

\subsubsection{Intertidal habitat}

The macrophytes observed at both the project area reaches and reference reaches included the green algae Cladophora sp. ("green tuft"), Enteromorpha sp. ("green string lettuce"), Ulva fenestrata ("sea lettuce"), and Prasiola sp. ("short sea lettuce"), and the brown algae Fucus gardneri (rock weed) and Pylaiella sp., with the highest richness observed in the reference area in 2008 and 2010 and in the Project Area in 2011, table 1. The dominant species in the reference area was $F$. gardneri, which ranged in coverage between intertidal elevation and years; the highest coverage occurred in the high intertidal in 2008 (mean $\pm \mathrm{SD}=$ $63 \pm 35 \%$ ) whereas coverage in the same zone in 2011 was $26 \pm 16 \%$. Increasing coverage by Cladophora sp. was observed in subsequent years (up to $8 \pm 11 \%$ in the mid intertidal in 2011).

In comparison to the reference area, macrophyte coverage in the Project Area was relatively low in 2008 and dominated by Prasiola sp. (up to $13 \pm 13 \%$ in the high intertidal), table 1 . In 2010, the macrophyte assemblage consisted of similar proportions of Cladophora sp. $(13 \pm 5 \%)$ and $F$. gardneri $(9 \pm 14 \%)$ in the high intertidal, with some $U$. fenestrata $(3 \%)$ in the low intertidal. F. gardneri was dominant in 2011 and with similar coverage to that in the reference area (15 to $26 \%$ coverage), and Cladophora sp. and $U$. fenestrata were still present in similar proportions as observed the previous year.

Sessile invertebrate species observed were Mytilus sp. (blue mussels) and Balanus glandula (acorn barnacles) and an unidentified oyster. The highest coverage of Mytilus sp. occurred in the mid intertidal zone of the reference area $(75 \pm 18 \%)$. Coverage was lower in the reference area in $2010(50 \pm 18 \%)$, and again in $2011(26 \pm 16 \%)$. B. glandula coverage was $15 \pm 0 \%$ in the high and low intertidal zones and $7.5 \pm 11$ in the mid in 2008 and in 2010 was $50 \pm 18 \%$ in the high zone and near zero in the low intertidal. In 2011, barnacle coverage ranged from 37 to $50 \%$ from the low to high zones. In the Project Area, M. edulis coverage increased from $3.6 \pm 5.2 \%$ in 2008 to $28 \pm 19 \%$ in 2011 , whereas $B$. glandula decreased from $52 \pm 28 \%$ in 2008 to $30 \pm 19 \%$ in 2011 . 
Table 1: Summary of coverage and richness of major categories among study areas and years.

\begin{tabular}{|c|c|c|c|c|c|c|c|}
\hline \multirow{3}{*}{\multicolumn{2}{|c|}{ Category* }} & \multicolumn{6}{|c|}{ Location / Intertidal Zone } \\
\hline & & \multicolumn{3}{|c|}{ Project Area $(n=7)$} & \multicolumn{3}{|c|}{ Reference $(n=2)$} \\
\hline & & High & Mid & Low & High & Mid & Low \\
\hline \multicolumn{8}{|c|}{2011} \\
\hline \multicolumn{2}{|c|}{ Bare substrate } & $40 \pm 20$ & $2.9 \pm 5.4$ & $2.9 \pm 5.4$ & $26 \pm 16$ & $0.5 \pm 0$ & $0.5 \pm 0$ \\
\hline \multirow{2}{*}{$\begin{array}{l}\text { Macro- } \\
\text { phyte }\end{array}$} & Cov. & $33 \pm 12$ & $37 \pm 16$ & $31 \pm 19$ & $27 \pm 16$ & $31 \pm 14$ & $25 \pm 12$ \\
\hline & Rich. & $2.6 \pm 0.8$ & $3.3 \pm 0.8$ & $4.3 \pm 0.8$ & $1.5 \pm 0.7$ & $3.5 \pm 0.7$ & $3.0 \pm 0$ \\
\hline \multirow{2}{*}{$\begin{array}{l}\text { Sessile } \\
\text { Invert. }\end{array}$} & Cov. & $25 \pm 13$ & $47 \pm 13$ & $60 \pm 23$ & $51 \pm 18$ & $7.8 \pm 3.9$ & $67 \pm 16$ \\
\hline & Rich. & $1.9 \pm 0.4$ & $2.1 \pm 0.4$ & $2.0 \pm 0$ & $2.0 \pm 0$ & $2.5 \pm 0.7$ & $3.0 \pm 0$ \\
\hline \multicolumn{2}{|c|}{ Total Coverage } & $59 \pm 20$ & $84 \pm 20$ & $91 \pm 23$ & $77 \pm 33$ & $100 \pm 9.9$ & $91 \pm 28$ \\
\hline \multicolumn{2}{|c|}{ Motile Invert. Rich. } & $2.4 \pm 1.0$ & $2.3 \pm 1.4$ & $2.7 \pm 1.5$ & $3.5 \pm 0.7$ & $3.5 \pm 0.7$ & $3.0 \pm 0$ \\
\hline \multicolumn{8}{|c|}{2010} \\
\hline \multicolumn{2}{|c|}{ Bare substrate } & $29 \pm 33$ & $13 \pm 12$ & $17 \pm 21$ & $3.0 \pm 0$ & $15 \pm 0$ & $9.0 \pm 8.5$ \\
\hline \multirow{2}{*}{$\begin{array}{l}\text { Macro- } \\
\text { phyte }\end{array}$} & Cov. & $22 \pm 15$ & $11 \pm 7.3$ & $11 \pm 6.4$ & $52 \pm 16$ & $20 \pm 1.8$ & $11 \pm 1.8$ \\
\hline & Rich. & $2.4 \pm 0.5$ & $3.7 \pm 0.5$ & $4.0 \pm 0.6$ & $2.5 \pm 0.7$ & $4.0 \pm 0$ & $5.0 \pm 0$ \\
\hline \multirow{2}{*}{$\begin{array}{l}\text { Sessile } \\
\text { Invert. }\end{array}$} & Cov. & $19 \pm 8.5$ & $47 \pm 27$ & $52 \pm 22$ & $17 \pm 1.8$ & $42 \pm 16$ & $25 \pm 8.5$ \\
\hline & Rich. & $2.0 \pm 0$ & $2.0 \pm 0$ & $2.1 \pm 0.4$ & $2.0 \pm 0.0$ & $2.5 \pm 0.7$ & $3.0 \pm 0$ \\
\hline \multicolumn{2}{|c|}{ Total Coverage } & $41 \pm 16$ & $58 \pm 27$ & $63 \pm 17$ & $69 \pm 17$ & $61 \pm 18$ & $36 \pm 10$ \\
\hline \multicolumn{2}{|c|}{ Motile Invert. Rich. } & $2.0 \pm 1.2$ & $2.4 \pm 1.0$ & $2.9 \pm 1.1$ & $3.5 \pm 0.7$ & $4.0 \pm 1.4$ & $2.5 \pm 0.7$ \\
\hline \multicolumn{8}{|c|}{2008} \\
\hline \multicolumn{2}{|c|}{ Bare substrate } & $46 \pm 36$ & $22 \pm 21$ & $26 \pm 21$ & $7.8 \pm 10$ & $3.0 \pm 0$ & $15 \pm 0$ \\
\hline \multirow{2}{*}{$\begin{array}{l}\text { Macro- } \\
\text { phyte }\end{array}$} & Cov. & $17 \pm 14$ & $14 \pm 10$ & $1.4 \pm 1.1$ & $64 \pm 36$ & $11 \pm 7$ & $12 \pm 8$ \\
\hline & Rich. & $2.0 \pm 0.8$ & $2.4 \pm 0.8$ & $1.3 \pm 0.5$ & $3.5 \pm 0.7$ & $2.0 \pm 0$ & $2.0 \pm 0$ \\
\hline \multirow{2}{*}{$\begin{array}{l}\text { Sessile } \\
\text { Invert. }\end{array}$} & Cov. & $33 \pm 28$ & $56 \pm 30$ & $50 \pm 29$ & $24.0 \pm 8.5$ & $83 \pm 7$ & $65 \pm 18$ \\
\hline & Rich. & $1.3 \pm 0.5$ & $1.9 \pm 0.4$ & $1.9 \pm 0.4$ & $2.0 \pm 0.0$ & $1.5 \pm 1$ & $2.0 \pm 0$ \\
\hline \multicolumn{2}{|c|}{ Total Coverage } & $50 \pm 30$ & $70 \pm 33$ & $51 \pm 29$ & $88 \pm 44$ & $93 \pm 0$ & $77 \pm 9$ \\
\hline \multicolumn{2}{|c|}{ Motile Invert. Rich. } & $1.3 \pm 1.1$ & $0.9 \pm 0.7$ & 0 & $1.5 \pm 0.7$ & $1.0 \pm 1.4$ & 0 \\
\hline
\end{tabular}

Notes: Values presented as mean \pm standard deviation $(\mathrm{SD}) ; *$ Cov. $=$ Coverage (as percent \%); Rich. $=$ Richness (as number of taxa); Invert. = Invertebrate.

Motile invertebrates observed included gastropods (snails and limpets), grapsid crabs, mites, amphipods and isopods. The highest richness (4 to 5 species) was observed at the reference locations as well as on Habitat Island.

Two NMDS dimensions were derived from the coverage data for the three sampling events which together accounted for $78 \%$ of the variance in the original similarity matrix. The stress value of the final configuration was 0.20 , which represents a good fit of the ordination results to the input data in qualitative terms [9]. Mytilus sp. coverage was strongly (i.e., $\left.\left|\mathrm{r}_{\mathrm{s}}\right|>0.6\right)$ positively, and bare substrate was strongly negatively, correlated with Dimension 1, whereas Cladophora sp. and F. gardneri were strongly negatively correlated with Dimension 2. Despite within year variability in both the reference area and the 
Project Area, each survey year generally grouped together, with a notable change in the Project Area from more bare substrate and less coverage by macroalgae in 2008 to increasing coverage by macroalgae and mussels, fig. 3. Moreover, in 2011, the intertidal community structure in the Project Area was relatively more similar to the reference area than previous years.

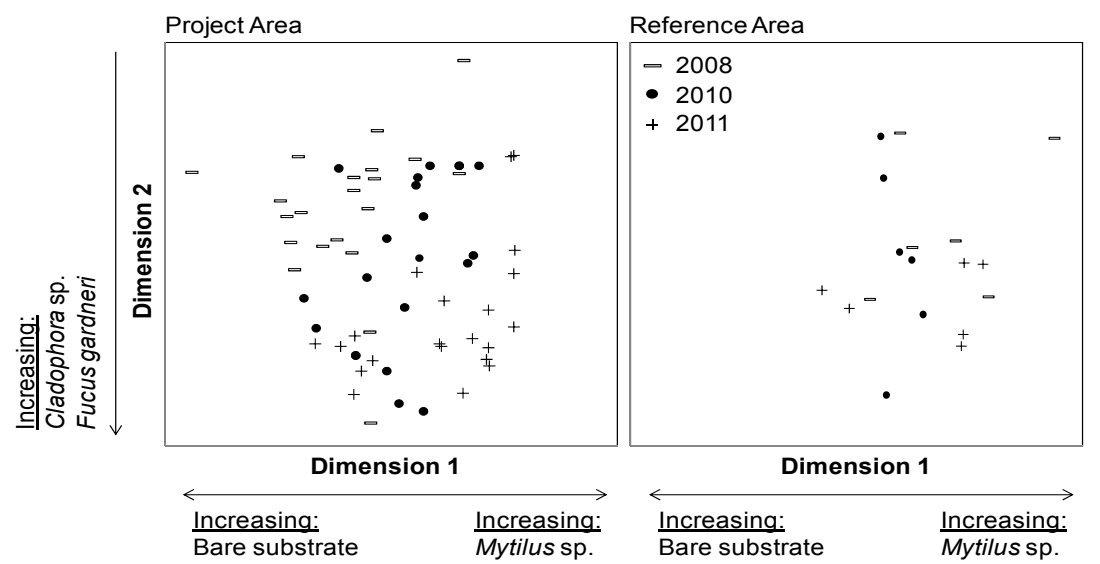

Figure 3: NMDS ordination plot showing variability in coverage of the SEFC intertidal zone by major indicator taxa among study years and areas. Taxa strongly correlated $\left(\left|\mathrm{r}_{\mathrm{s}}\right|>0.60\right)$ with each dimension are noted.

\section{Discussion}

The redevelopment of the SEFC lands, guided by the City of Vancouver's ODP for SEFC (e.g., liveability and ecological health), provided an opportunity to simultaneously incorporate ecological, economic, and human values into a single large project. It also presented an opportunity to document the success and rate of colonization of compensatory habitats and to provide compelling data to demonstrate the value of embedding ecological design with urban design. The three annual surveys conducted to date have confirmed that the aquatic habitat goal [4] is in the process of being achieved.

The constructed habitat in SEFC continues to colonize, following a typical successional pattern for intertidal communities in Western Canada, with barnacles first settling on the bare substrate, followed by macroalgae. These early colonisers then begin to support an assemblage of other species that can be important structural elements of fish habitat and food sources for fish, for example, amphipods $[10,11]$, which have been noted in the quadrats, as well as personally observed by the authors in notable numbers in the gravel substrate of the intertidal channels along Habitat Island.

The monitoring program also documents the dynamic nature of intertidal community structure in False Creek; coverage by the major indicator taxa discussed above also varied notable among survey areas, transects and years. 
Fish usage of the habitat can also be dynamic, reflecting temporal variability in salmonid migration from natal streams to the marine environment [11]. As observed at other sites in the Vancouver area, intertidal coverage can change dramatically between years due to factors unrelated to the habitat or activities at the site [12]. For example, although species living in the intertidal zone are adapted to changes in salinity such as may occur during rainfall and the development of a low-salinity surface layer, rapid or prolonged variations from the average condition can result in osmotic stress [e.g., 13, 14]. Total monthly rainfall in Vancouver was notably different between survey years, fig. 4, and along with other abiotic and biotic factors may have contributed to the variability observed.

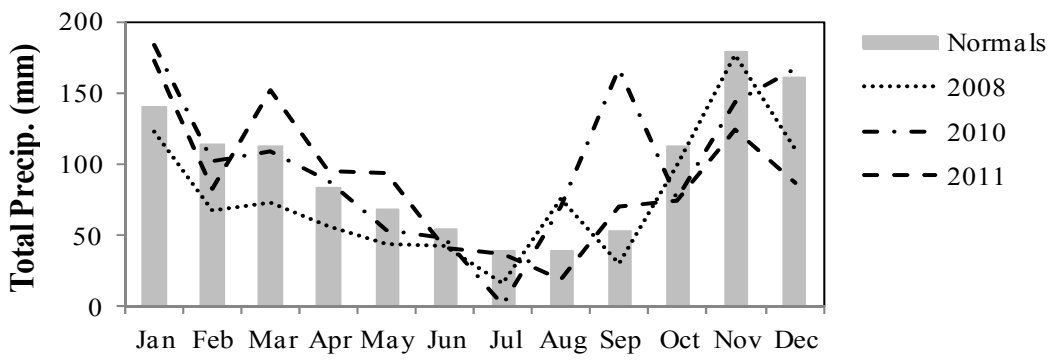

Figure 4: $\quad$ Monthly total precipitation in 2008, 2010, and 2011 (at Vancouver International Airport - Meteorological Survey of Canada Station WMO ID 71892). Normals are long-term averages of data from 1971 to 2000 .

Although the construction of Habitat Island and reconfiguration of the remainder of the shoreline was driven primarily by the management of fish habitat, the redevelopment of the shoreline in SEFC also contributed to the objectives of the ODP in other ways. For example, SEFC has received increasing positive attention in the community and the media. An internet search returns links to news articles, blogs and notices attributing events such as the first Pacific herring (Clupea pallasi) spawn along the SEFC shoreline in recent memory, as well as the presence of raptors and migratory water birds to the improvements in habitat and water quality. In addition, the redevelopment of these lands has transformed what was a "typical" chain-link-fenced brownfield site into an attractive public realm with enhanced property and ecological values.

\section{Summary}

The SEFC lands in Vancouver had a long history of industrial activity that affected the environmental quality of False Creek, both through filling that changed the physical condition of habitat as well as through the introduction of contaminants. The redevelopment of the area was guided by the City of Vancouver's ODP, which emphasized community values of improved public access to the shoreline, fish habitat, and health and safety, and included 
remediation of site contamination, shoreline stabilization and construction of compensatory habitat. The post-construction monitoring program undertaken to evaluate the function of the constructed habitat indicates through the observed colonization by macroalgae and encrusting invertebrate species that, with thoughtful planning and design, brownfield sites can be transformed to provide an engaging human place with significant economic and ecological benefits.

\section{References}

[1] City of Vancouver, Southeast False Creek: a historical overview. November 1998. Online www.city.Vancouver.bc.ca/commsvcs/currentplanning/ sefc/history.htm

[2] Morrow Environmental Consultants Inc., Revised remediation plan, Southeast False Creek, overall site redevelopment, Vancouver, BC. Unpublished consultant's report. 2005.

[3] Department of Fisheries and Oceans, The Department of Fisheries and Oceans policy for the management of fish habitat, DFO, Ottawa, ON. 1986.

[4] Adams, M., Wernick, B., and Nikl, L., Design of natural features along a remediated shoreline: redevelopment of the Southeast False Creek Lands in Vancouver, Canada, in preparation for Environmental Impact 2012.

[5] Naito, B.G. and Hwang, J., Timing and distribution of juvenile salmonids in Burrard Inlet, British Columbia: February to August 1992, Canadian Data Report of Fisheries and Aquatic Sciences 1069, 74 p., 2000.

[6] Graham, L.E. and Wilcox, L.W., Algae, Upper Saddle River, NJ, 2000.

[7] Druehl, L., Pacific Seaweeds: A Guide to Common Seaweeds of the West Coast, Madeira Park, BC, 2000.

[8] Kozloff, E.N., Seashore Life of the Northern Pacific Coast, University of Washington Press: Seattle, WA, 1983.

[9] Clarke, K.R., Non-parametric multivariate analyses of changes in community structure. Aust. J. Ecol., 18, 117-143, 1993.

[10] Nassichuk, M.D., Structural and interactive relationships between intertidal Fucus populations and associated faunal assemblages, M.Sc. thesis, University of British Columbia: Vancouver, Canada. 139 p. 1975.

[11] Groot, C. and Margolis, L. (eds). Pacific Salmon Life Histories, UBC Press: Vancouver, Canada, 1991.

[12] Wernick, B.G., Nikl, L.H., Seguin, S.R., and Sinnett, G., Britannia Mine remediation project - integrating ecological monitoring with remediation activities. Proc. of $5^{\text {th }}$ Int. Conf. on Mine Closure, eds. A. Fourie, M. Tibbett, and J. Wiertz, Australian Centre for Geomechanics, Perth, pp. 303$316,2010$.

[13] Kamer, K., and Fong, P., A fluctuating salinity regime mitigates the negative effects of reduced salinity on the estuarine macroalga, Enteromorpha intestinalis (L.) link. J. Exp. Mar. Biol. Ecol., 254, pp. 53-69, 2000.

[14] Qiu, J.-W., and Qian, P.-Y., Tolerance of the barnacle Balanus amphitrite amphitrite to salinity and temperature stress: effects of previous experience. Mar. Ecol. Prog. Ser. 188, pp. 123-132, 1999. 